\title{
FATIGUE STRENGTH DEGRADATION OF THERMOMECHANICALLY ROLLED HIGH STRENGTH STEELS WELDS
}

\author{
Filip KLEJCH, Eva SCHMIDOVÁ \\ Department of Mechanics, Materials and Machine Parts, Faculty of Transport Engineering, University of \\ Pardubice,Czech Republic,EU, filip.klejch@upce.cz, eva.schmidova@upce.cz
}

https://doi.org/10.37904/metal.2021.4141

\begin{abstract}
The good weldability of thermomechanically rolled high-strength steels is vital for contemporary steel structures. Full utilization of their capacity requires detailed knowledge and quantification of all processes that are involved by the heat-deformation cycle during welding. As good cold-formability is one of their promoted capabilities, residual stress gradient after forming to particular profile has the non-negligible effect on the dynamic resistance of welded joints.

In this study, the dynamically stressed structural unit made of ALFORM 700M steel was investigated, where the initiation of fatigue damage during experimental test in connection with the degrading effect of welding was determined. Invoked processes are evaluated using structural analyzes. The heterogeneity of mechanical parameters is expressed by the local yield strength measured by the indentation method. Fractographic analysis of the initiation process and individual stages of fracture development reflects the influence of both welding and the initial quality of the steel.
\end{abstract}

An important role of the residual stress of the formed profile is found out, leading to a limited extent to the delamination of the material during welding and thus decisively affects the fatigue resistance.

Keywords: High strength steels, thermomechanically rolled steels, delamination of rolled profile, weldability, indentation

\section{INTRODUCTION}

Microalloyed and thermomechanically rolled steels presents one of the most important material concepts for high-strength steels development. Weldability and cold-formability are the main potentials and the welded hollow-sections parts thereby play a the key role in structures. Furthermore, these hollow sections are critical for energy absorbent parts in contemporary automotive applications, where welding is still the most common joining method. Their increasing application is essential for the design of construction to increase the strength to weight ratio and at maintain or even improve safety standards, i.e., for automotive structures, trucks, cranes and ships [1,2].

Microalloyed and thermomechanically rolled steels are standardised according to EN10149-2. These steels are widely used, but their correct application requires detailed knowledge and quantification of the welding process influence. An imperfect design of the welded joint, even in combination with the internal stress after cold forming, can significantly affect the fatigue resistance of structural units. Due to the high-temperature sensitivity of these steels, many studies reported the need for heat input limitation and cooling rate control [3-7].

On the one side, the degradation of high-strength thermomechanically-treated steels due to the welding process, particularly softening [3,8], decrease in toughness [8], cold cracking [9] or lack of ductility [3] are well defined. However, on the other side, the development of pre-strains in hollow sections is an unavoidable effect, which is thus far not precisely included in the normative rules for cold-formed areas and welding technologies 
validations. Although some limitations of hollow-sections producers in minimal diameter/radius/thickness are met, the final effect on residual stress, microstructural parameters and increased dislocation density leads to the different capabilities of energy consumption during welding. So the prediction of the complex influence of the welding together with the pre-strain effect of bent hollow-section parts is of the utmost importance.

Localised differences in stiffness and residual stress increase the requirements on the metallurgy capacity for energy absorption by microplasticity, which is decisive for final fatigue response. The presence of a welded joint reduces the fatigue resistance depending on the heat input during the welding [10,11,12]. Afkhami et al. [3] reported the influence of different pre-strain intensity on the structural and mechanical parameters induced by gas-metal arc welding.

This paper aims to introduce the method to assess the complex state of ALFORM 700M steel after welding, considering the effect of cold forming. The dynamically tested unit in this study contained a welded joints adjacent to the hollow-sections bending, which combined the mentioned issues and led to premature fatigue fracture. The combined influence of welding and pre-strain effect is measured in local differences in residual plastic capacity.

\section{MATERIAL AND METHODS}

Welded joints of hollow sections, dimensions $90 \times 380 \mathrm{~mm}$, thickness of $6 \mathrm{~mm}$, made of steel grade of ALFORM $700 \mathrm{M}$ were performed under the GMAW method (the OK Autrod 12.64 filler mat./M21 shielding gas). The chemical composition of the analysed steel is given in Table 1.

A combination of optical and scanning electron microscopy with energy-dispersive X-ray spectroscopy was used for structural analyses. Metallographic sample preparation consisted of mechanical grinding and polishing; used etching $-3 \%$ Nital. The fractographic analysis served to assess the fracture mechanism, initiation and fatigue cracks propagation. The hollow-section delamination influence, which was determined to be very significant, was analysed in connection with fracture initiation.

Table 1 Chemical composition (wt \%)

\begin{tabular}{ccccccccccccc}
\hline & $\mathbf{C}$ & $\mathbf{M n}$ & $\mathbf{S i}$ & $\mathbf{P}$ & $\mathbf{S}$ & $\mathbf{C r}$ & $\mathbf{N i}$ & $\mathbf{A l}$ & $\mathbf{T i}$ & $\mathbf{M o}$ & $\mathbf{N b}$ & $\mathbf{V}$ \\
\hline $\begin{array}{c}\text { Analysed } \\
\text { steel }\end{array}$ & 0.067 & 1.89 & 0.026 & 0.0074 & 0.0010 & 0.025 & 0.0066 & 0.046 & 0.130 & 0.0059 & 0.049 & 0.0068 \\
$\begin{array}{c}\text { Alform 700 M } \\
\text { (max.) }\end{array}$ & 0.12 & 2.1 & 0.50 & 0.02 & 0.008 & 0.30 & 0.30 & & 0.20 & 0.30 & 0.08 & 0.15 \\
\hline
\end{tabular}

To quantify the influence of welding technology, both conventional Vickers hardness measurement (HV0.5) and Depth Sensing Indentation (DSI) cylindrical tests were performed in the fatigue crack initiation zone. The hardness gradient and the local yield strength were measured in lines perpendicular to the fusion zone. An unconventional cylindrical indenter with a diameter of $0.5 \mathrm{~mm}$ at a load of $600 \mathrm{~N}$ was used for indentation tests. The indentation yield stress is determined using the analytical definition of shear deformation under the contact surface, according to Hencky's hypothesis $[13,14]$. The standard tensile test in the longitudinal and perpendicular orientation of the uninfluenced hollow-section part served as a final validation.

\section{RESULTS AND DISCUSSION}

\subsection{Structural influence of welding}

The uninfluenced microstructure shows a fine ferritic microstructure with partial grain deformation after forming (Figure 1(a)). The fine precipitates, together with the microalloying elements in solution, delay the recrystallisation of the deformed austenite. The hardening mechanism is mainly based on the contributions of 
the solid solution hardening, precipitation hardening by titanium-niobium carbonitrides $(\mathrm{Ti}, \mathrm{Nb})(\mathrm{C}, \mathrm{N})$, grain refinement and dislocation hardening. The analysed material contains relatively coarse carbides of the TiN type, resp. TiNC.

The range of the heat-affected zone (HAZ) in relation to the hollow section radius is displayed in Figure 1(b). Imperfect root fusion did not reduce the strength of the joint in this case; no fatigue cracks were found in the root. Due to the effect on fatigue resistance, the fundamental changes in the geometry and size of the grain and the phase changes in response to the achieved cooling rate are mainly in the zone along the fusion line. The decisive sublayer's microstructure is displayed in Figures 1(c),(d). The coarsened region, adjacent to the fusion line, consists mainly of ferrite laths, decomposed upper bainite, and martensite (Figure 1(d)). The full recrystallization was reached in the grain refinement zone (Figure 1(c)). For the Alform700M, incomplete recrystallization is desired during the finishing rolling to utilise the strengthening mechanisms. The relatively low content of micro-alloying elements supports the recrystallization resulting from welding. Heating to normalization temperatures did not lead to radical grain refinement compared to the initial stage. The observed reduction of the ferrite acicularity means the deterioration effect in terms of strength and toughness.
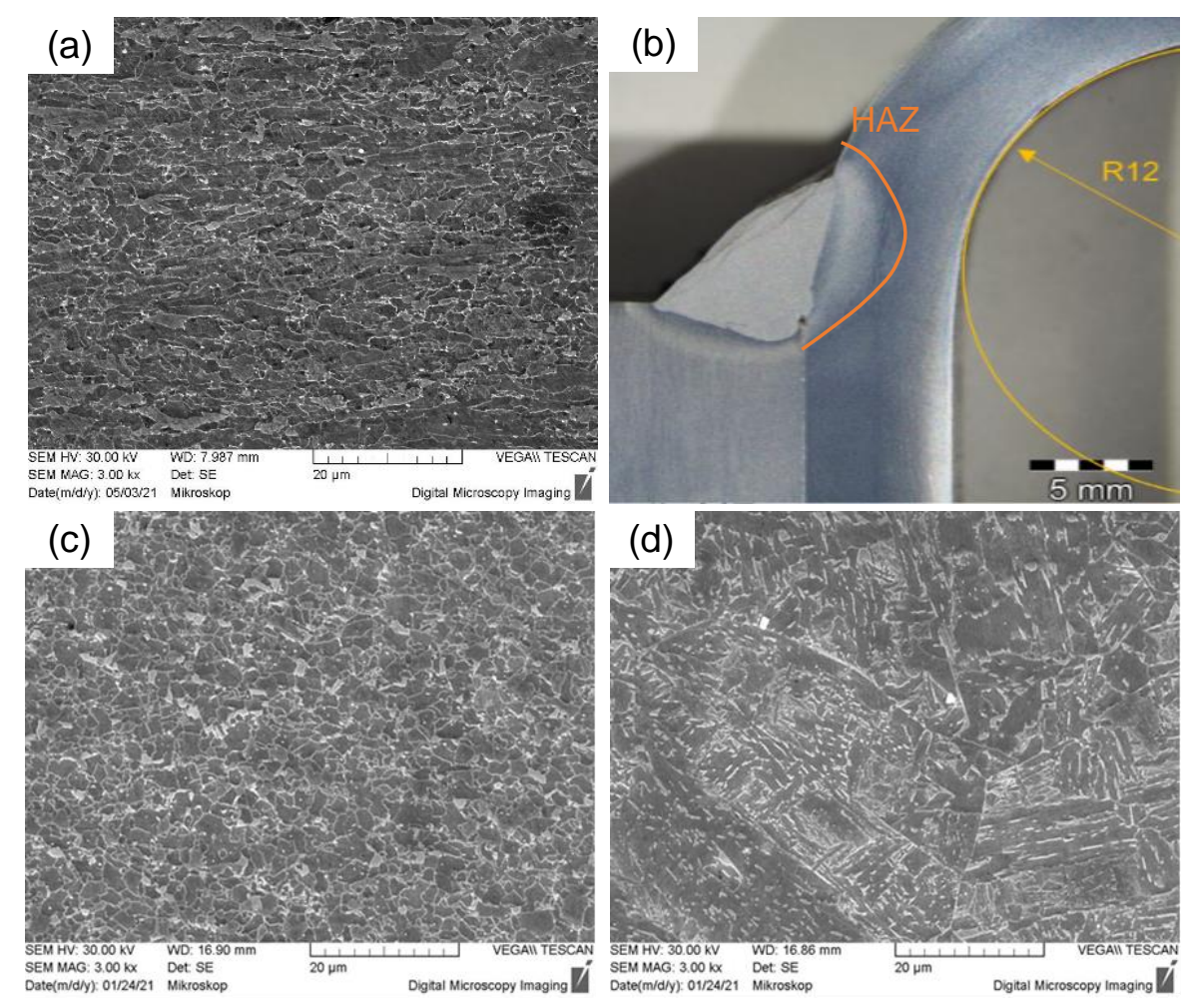

Figure 1 Structural effects of welding (a) parent steel, (b) Position of welded joint vs bending of the hollow profile, (c) grain refinement zone, (d) coarsened region

\subsection{Fractography Analyses, Effect Of Delamination}

Two different fatigue initiation sources were distinguished when examining the fracture surface. Delamination of the hollow section along the bent part was discovered due to the collision of the pre-strain effect with the thermal stress after welding. The shear fracture mode of the initial delamination is shown in Figures 2(a, b).

Consequently, the fatigue resistance was limited by multiple initiations of fatigue cracks on the inner surface of the hollow section and on the surface of delamination at the same time. The cracks propagated towards the weld interface under specific stress-strain conditions. Only to a minimal extent was the fatigue crack initiated directly at the weld interface, i.e., due to the prevalence of the welding degradation effect, Figure 2(c). 
In contrast, in the part where was found no delamination of the welded hollow section, was the initiation of a fatigue crack in the zone along the fusion line (coarsened region). The development of the crack then propagated across other layers of the HAZ into the base material. The delamination effect thus significantly affected the way the fatigue crack development.
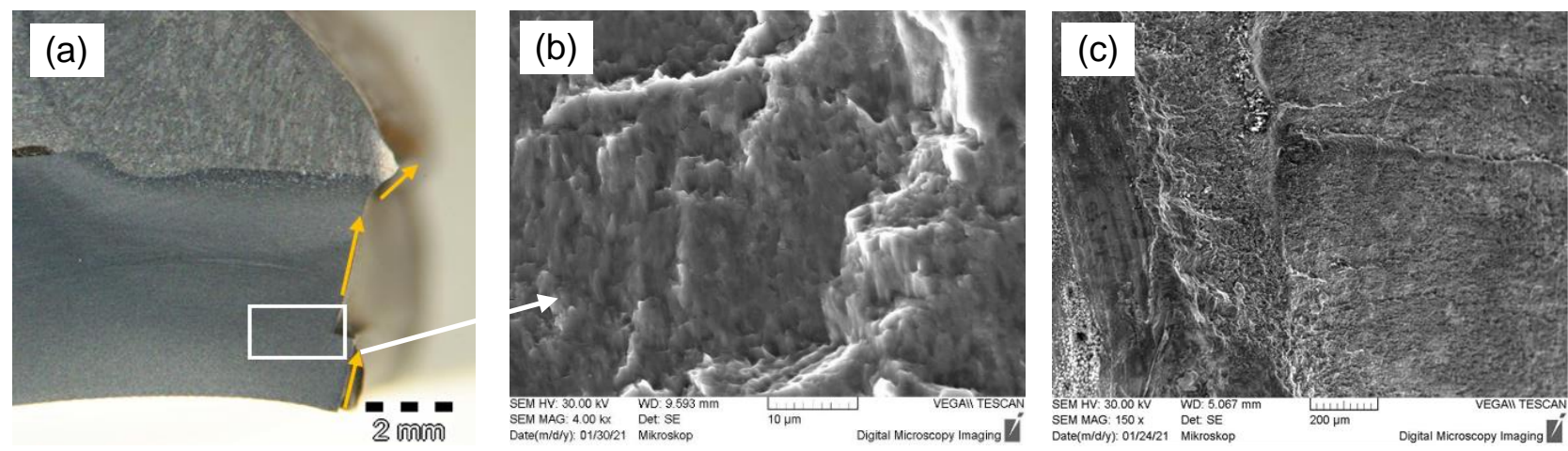

Figure 2 Fatigue crack development under influence of pre-strain effect; (a) path of fatigue crack propagation, (b) shear fracture in delamination, (c) initiation along the fusion zone

\subsection{Hardness and local yield stress measurement}

The hardness gradient of the HAZ confirms the results of metallographic analyses, see Figure 3. The loss of hardness in the grain refinement section was discovered up to $18 \%$ with the respect to the pre-strained material. The increase in hardness was located in a coarsened region along the fusion line. The hardness in this section corresponds to the hardness of the base material, but due to the structural change of the grain, a lower impact resistance can be expected. The scattering of the values in the area of the base material is caused by the influence of the preserved anisotropy after thermomechanical rolling. The position of local hollow section delamination is shown in Figure 3, det. A. It can be seen that the fatigue crack developing from the interior of the profile to the free surface of the material was deflected along the interface of the two sublayers of the heat affected zone (hardened vs. softened) - Figure 3, det B.

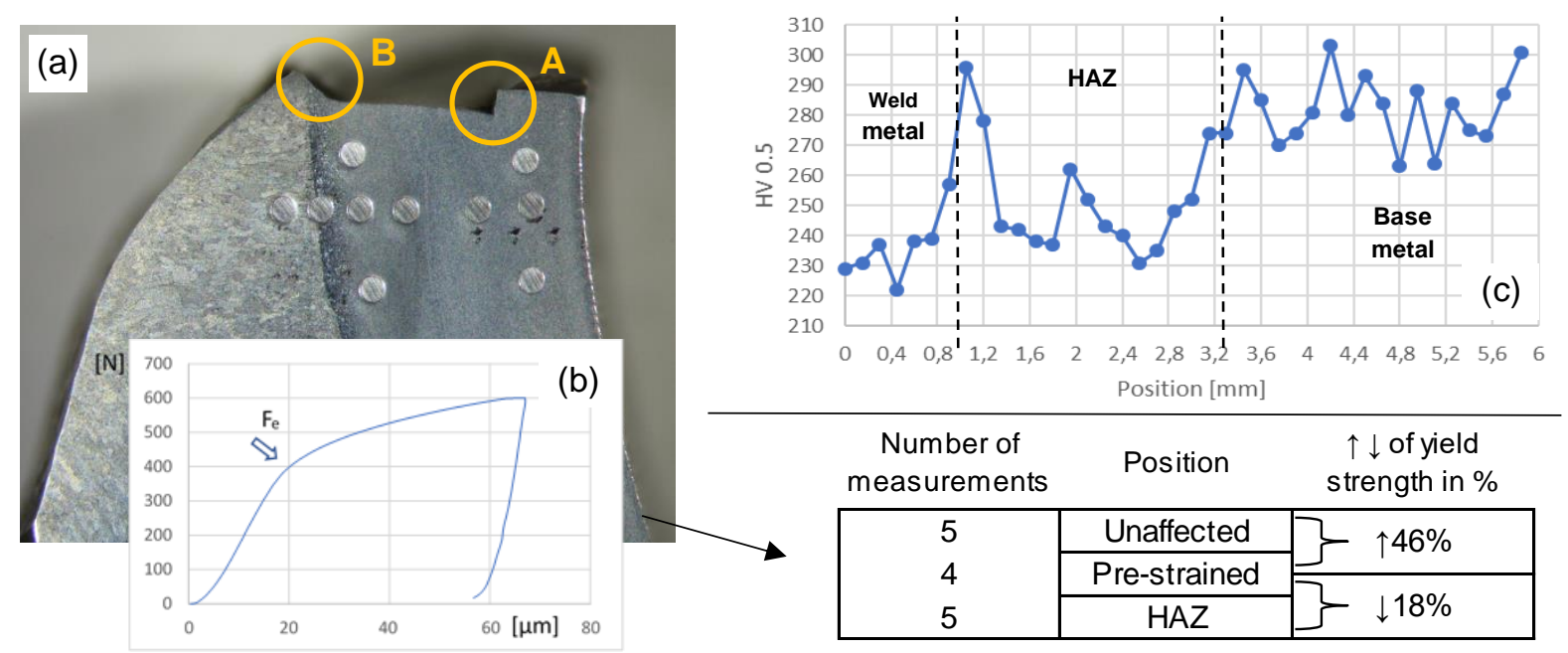

Figure 3 Welding vs. pre-strain effect quantification in HAZ (a) referential positions of DSI, (b) yield force determination, (c) hardness gradient through the fusion zone

The values of the local yield strength were determined from the indentation tests, see Figure 3 . The standard tensile tests were used for validation. The differences between the detected values correspond to the hardness 
gradient. The larger area of the indenter body partially suppressed the scattering of the hardness values. The local yield strength decrease in HAZ was found out up to $18 \%$ with the respect to the pre-strained material, while the place of decrease corresponds to the grain refinement zone. A comparison of the unaffected and the pre-strained material showed a significant local yield strength increase due to cold forming. The yield strength of the pre-strained material was found out to be up to $46 \%$ higher in comparison to the unaffected material. This effect in combination with welding led to the delamination of the hollow section; no reference to the structural or chemical heterogeneity supporting the delamination, was found.

Thus the local mechanical properties in the critical zone (fatigue initiation zone) are derived from the complex influence of welding and pre-strain effect after cold forming. Deterioration of a primary dislocation enriched ferrite in the normalization layer leads to the sharp gradient along the fusion zone. So it is the priority effect for fatigue cracks initiations. In case of the pre-strain cooperative effect, the deformation of the fine grains together with the presence of carbides increases the overall strength of the steel. The thermal stress due to the welding can then immediately lead to cracks formation prior to operational loading.

\section{CONCLUSIONS}

The combined effect of welding and cold forming on the fatigue initiation process was described for hollowsection from thermo-mechanically treated ALFORM 700M steel. Structural and fractographic analyses identified the degradation mechanisms involved. DSI and hardness measurement was performed to quantify the localised effects. The following conclusions can be derived from the performed analyses:

- While the recrystallisation of the thermomechanically processed steel, as a key degradation effect of welding, led to the softening in HAZ, the pre-strain caused a contrary effect in terms of strength and stiffness. Due to the applied welding technology, a significant decrease in strength was found; in hardness values and local yield strength by $18 \%$ with the respect to the pre-strained material.

- A comparison of the unaffected and the pre-strained material showed a significant increase in local yield strength due to cold forming - pre-strained up to $46 \%$ higher in comparison to the unaffected material.

- The initiation and development of the fatigue crack was influenced by the initial discontinuity of the profile material. This delamination of the material in the region of the profile radius led to the initiation of fatigue cracks on the inner surface, and thus a reduction in fatigue resistance.

- The formation of delamination was a reaction to the stress state of the material after cold forming and welding.

- The depth Sensing Indentation test using the cylindrical indenter was proved as a suitable method to distinguish the pre strain vs. welding influence on the fatigue initiation process. When supplemented with calibration by a static test, it is a reliable method for quantifying the localised degradation effect.

\section{ACKNOWLEDGEMENTS}

This work was supported by the project Number SGS_2021_010.

\section{REFERENCES}

[1] KAH, P., PIRINEN, M., SUORANTA, R., MARTIKAINEN, J. Welding of Ultra High Strength Steels. AMR. [online]. 2013, vol. 849, pp. 357-365. Available from: https://doi.org/10.4028/www.scientific.net/amr.849.357.

[2] High-strength and ultra-highstrength thermomechanically rolled fine-grained steels: Technical terms of delivery for heavy plates. VOESTALPINE GROBBLECH GMBH. 2014.

[3] AFKHAMI, Shahriar, BJÖRK, Timo, LARKIOLA, Jari. Weldability of cold-formed high strength and ultra-high strength steels. Journal of Constructional Steel Research [online]. 2019, vol.158, pp. 86-98 [cit. 2021-03-28]. Available from: https://doi.org/10.1016/j.jcsr.2019.03.017. 
[4] ZAVDOVEEV, A., V. POZNIAKOV, M. ROGANTE, M. SKORYK, ALEKSEENKO I. Study of the welding thermal cycle for HSLA steel grade alform plate 620M: structure and mechanical properties. Mechanical Technology and Structural Materials [online]. 2019, vol. 70, pp. 145-149. [cit. 2021-03-28]. ISSN 1847-7917.

[5] DOBOSY, Ádám, LUKÁCS, János. The Effect of the Welding Parameters on the Properties of Thermomechanically Rolled High Strength Steels. In: The publications of the MultiScience - XXX. MicroCAD International Scientific Conference [online]. University of Miskolc, 2016. [cit. 2021-03-28]. ISBN 9789633581131. Available from: https://doi.org/10.26649/musci.2016.079.

[6] GÓRKA, Jacek. Influence of the maximum temperature of the thermal cycle on the properties and structure of the HAZ of steel S700MC. IOSR Journal of Engineering. 2013, vol. 3, no. 11, pp. 22-28. ISSN 22788719. Available from: https://doi.org/10.9790/3021-031142228.

[7] GÓRKA, J. Weldability of Thermomechanically Treated Steels Having a High Yield Point. Archives of Metallurgy and Materials [online]. 2015, vol. 60, no. 1, pp. 469-475. [cit. 2021-03-28]. ISSN 2300-1909. Available from: https://doi.org/10.1515/amm-2015-0076.

[8] KURC-LISIECKA, A., PIWNIK, J., LISIECKI, A. Laser Welding of New Grade of Advanced High Strength Steel STRENX 1100 MC. Archives of Metallurgy and Materials [online]. 2017, vol. 62, no.3, pp. 1651-1657. [cit. 202103-29]. ISSN 2300-1909. Available from: https://doi.org/10.1515/amm-2017-0253.

[9] GARAŠIĆ, I., ĆORIĆ, A. KOŽUH, Z. SAMARDŽIĆ, I. Occurrence of cold cracks in welding of high-strength S960 QL steel. Tehnički vjesnik . 2010, vol. 17, no.3, pp. 327-335.

[10] ŠEBESTOVÁ, H., HORNÍK, P., MRŇA, L., JAMBOR, M., HORNÍK, V., POKORNÝ, P., HUTAŘ, P., AMBROŽ, O., \& DOLEŽAL, P. Fatigue properties of laser and hybrid laser-TIG welds of thermo-mechanically rolled steels. Materials Science and Engineering A-structural Materials Properties Microstructure and Processing. [online]. 2019, vol. 772, p. 138780. Available from: https://doi.org/10.1016/.msea.2019.138780.

[11] LAHTINEN, T., SILVA, P.V., \& INFANTE, V. Fatigue behavior of MAG welds of thermo-mechanically processed 700MC ultra high strength steel. International Journal of Fatigue. [online]. 2019, vol. 126, pp. 62-71. Available from: https://doi.org/10.1016/J.IJFATIGUE.2019.04.03.4

[12] DOBOSY, Ádám, LUKÁCS, János. Welding Properties and Fatigue Resistance of S690QL High Strength Steels. Materials Science Forum [online]. 2015, vol. 812, pp. 29-34 [cit. 2021-03-28]. ISSN 1662-9752. Available from: https://doi.org/10.4028/www.scientific.net/MSF.812.29.

[13] BOWMAN, KEITH, J. Mechanical behavior of materials. Hoboken, NJ: John Wiley, 2004, xi. 334 p. ISBN 0471241989.

[14] HANUS, Petr, SCHMIDOVÁ Eva, SCHMID Michal. The Possibility of Evaluating the Yield Strength Through Indentation. In: Proceedings 24th International Conference on Metallurgy and Materials. Brno, 2015, s. 476-481. ISBN 978-80-87294-58-1. ISSN 2694-9296. 